\title{
Leyendo a Rodolfo Kusch en y desde Australia. Lecturas y reflexiones
}

\section{Reading Rodolfo Kusch in and from Australia. Readings and reflections}

\author{
Roberto Hernan Esposto \\ University of Queensland (Brisbane, Australia) \\ r.esposto@uq.edu.au
}

Resumen: Leer en Australia el pensamiento situado de un filósofo americano como Rodolfo Kusch puede parecer algo insólito. No obstante, el objetivo de este escrito es el de compartir una serie de reflexiones de nuestras lecturas de Kusch desde la experiencia de un sujeto que habita «entre mundos» o bien en una «doble consciencia». Nuestro camino ha sido motivado y aclarado por una penetrante observación de Eduardo A. Azcuy cuando afirma que la invitación de Kusch «a pensar América y pensar, asimismo, desde América en americano, lejos de constituir una presunción localista significa una reivindicación del pensar mismo concebido como algo genuino y universalizante. Por histórica ironía ese pensar se convierte así, en esta hora de crisis de la humanidad, en un pensar para el mundo» (1989: 7)

Palabras clave: Rodolfo Kusch, pensamiento situado, colonialidad, Argentina, Australia

Abstract: To read in Australia the situated thought of a Latin American philosopher like Rodolfo Kusch may seem rather odd. However, the aim of this article is to share a series of reflections of our readings of Kusch which emerge from the experience of a subject who lives «between worlds» or dwells in a «double consciousness». Our path has been cleared and also motivated by Eduardo A. Azcuy's insight when he asserts that Kusch's invitation «to think America from America and from an Americano standpoint, far from being a parochial presumption, is indeed an assertion that thought can be genuinely conceived of as universal. Due to the ironical turn of history, this thought has now become, at this juncture in the crisis of humanity, as a way to think the world» (1989: 7).

Keywords: Rodolfo Kusch, situated thought, coloniality, Argentina, Australia. 
Hijo de padres alemanes, Günther Rodolfo Kusch (1922-1979) nació en Buenos Aires, fue poeta y dramaturgo, filósofo y antropólogo. Egresado en Filosofía por la Universidad de Buenos Aires, fue autor de ocho libros, de los que se destacan La seducción de la barbarie (1953), América profunda (1962), El pensamiento indígena y popular (1971) y Geocultura del hombre americano (1976). Podemos situar su pensamiento y su trabajo en un momento de encrucijada histórica a mediados del siglo pasado cuando el modelo argentino de modernidad (léase positivismo anglofrancés) y sus estructuras socioeconómicas agroexportadoras entran en crisis, provocando un malestar generalizado en la sociedad. Su pensamiento también coincide en este país y en el resto del continente americano con el surgimiento de movimientos políticos y sociales de tendencias nacionalistas y populares. Al mismo tiempo, luego de la Segunda Guerra Mundial, entra asimismo en crisis el humanismo europeo, del cual la Argentina había bebido abundantemente. Todo esto coincide con el desmoronamiento de los poderes colonialistas e imperiales decimonónicos europeos (Gran Bretaña y Francia) y una concientización anticolonialista (por ejemplo, Franz Fanón) en África y Asia.

Kusch fue un raro y un hereje en el panorama intelectual y académico argentino de su época, desarrollando así un pensamiento heterodoxo. Un dato convalida esto: no continúa su carrera académica en Europa. Luego de la llamada Revolución Libertadora (1955), nuestro autor comienza a abrir un camino que lo conduce hasta los últimos días de su vida a la puna del noroeste argentino, Bolivia y Perú. Este accionar sería visto como un acto de herejía epistemológica. Lo que se dispone a hacer nuestro autor es emprender un periplo, con la formación intelectual adquirida en la capital, en una época de crisis ética y de represión política, en el que se replantea — nadas más y menos - lo que Enrique Dussel acuña como los «núcleos problemáticos universales». Estos núcleos, sostiene este filósofo, son el «conjunto de preguntas fundamentales (es decir, ontológicas) que el homo sapiens» se ha hecho desde que le amaneció la conciencia de sí mismo en el cosmos (2015: 11-12).

Consecuentemente, Kusch se dispone a buscar y escuchar, trazar y articular un pensamiento situado en América y desde América, cuyo camino fue el de hurgar y cuestionar para exponer a la luz del día la interiorización de la colonialidad de nuestra modernidad para luego bifurcarse e iniciar una reflexión descolonial, para ir desprendiéndose de los patrones de la modernidad occidental. En el prólogo a la primera edición de América profunda escribe:

«Numerosos viajes al altiplano y la investigación sobre religión precolombina, limitada a las zonas quichua y aimara, me dieron la pauta de que había hallado probablemente las categorías de un pensar americano [...]. De ahí [...]que surge la firme convicción 
sobre la continuidad del pasado americano en el presente [...]. [El] estudio del problema me ha llevado a remover estructuras ignoradas por nuestros investigadores universitarios. Indudablemente se trata de una aventura que está al margen de nuestra cultural oficial. El pensamiento como pura intuición implica, aquí en Sudamérica, una libertad que no estamos dispuestos a asumir [...]. La intuición que bosquejo aquí oscila entre dos polos. Uno es el que llamo ser, o ser alguien, y que descubro en la actividad burguesa de la Europa del siglo xvi y, el otro, el estar, o estar aquí, que considero como una modalidad profunda de la cultura precolombina [...]. Ambas son dos raíces profundas de nuestra mente mestiza [...]. Empleé en mi exposición un estilo intencionalmente a la vez literario y técnico, porque esta es la única manera de explicar la intuición que dio origen a este trabajo. Se debe ello a la falta de antecedentes serios en este terreno del pensar americano» (1962: $5-8)$.

Nuestro autor pretende deconstruir el relato de la cultura oficial cuya máxima expresión encontramos en el relato fundacional de la nación moderna. En América, el relato modernizador, civilizatorio (a veces conocido como civilización y barbarie, progreso y tradición) ha servido para cubrir y obnubilar un mundo y un modo de pensar ancestral. Por tanto, la meta de Kusch ha sido la de ir tras las huellas del pasado en el mundo contemporáneo argentino y americano. Dada esta meta, la deconstrucción que Kusch hace de la modernidad a lo largo de su obra, a nuestro modo de ver, puede utilizarse como un modo para principiar un itinerario crítico de otras sociedades que han experimentado procesos similares. Al hacer esta lectura, uno se dispone a hacer una crítica transversal, sur-sur, de nuestro autor, estando en Australia; leyendo a Kusch y pensando críticamente en Australia.

Hechas estas exposiciones introductorias sobre el pensamiento kuscheano, a continuación intentaremos contestar y meditar sobre la pregunta que encabeza este escrito, que en última instancia pretende problematizar el pensamiento de nuestro autor en otras latitudes.

¿Qué quiere decir leer a Kusch en y desde Australia? Hacerse esta pregunta puede parecer algo raro a primera vista, especialmente si se lee a nuestro autor exclusivamente dentro de un marco de particularidades o esencialidades culturales, puesto que hemos dicho que Kusch es un pensador situado en el suelo americano. Pero así caeríamos en la trampa que nos pone en el camino un pensador de tendencia neoliberal como Mario Vargas Llosa, quien asegura que «una de las obsesiones recurrentes de la cultura latinoamericana ha sido definir su identidad» cuya «manía por determinar la especificidad histórico-social o metafísica de un conjunto gregario ha hecho correr océanos de tinta en América latina» (Vargas Llosa, 2005). 
Pero la afirmación de Vargas Llosa es motivo de otras preguntas: ¿acaso pensadores europeos no se han interrogado por su identidad por decenios? Por cierto, además de haber definido su pensamiento como filosofía, ¿acaso Europa no lo ha definido otorgándole el valor de universal? Dudamos que el premio Nobel hubiese pensado lo mismo de la fecunda tradición británica que se atribuye un metafísico destino manifiesto anglosajón que reza de que corre en sus venas un instinto por la libertad y la democracia parlamentaria de Westminster (aunque la Cámara de los Lores sea por asignación vitalicia).

Por lo demás, en el ámbito anglobritánico: «Es habitual — dice John H. Hobsonque demos por sentado que el Occidente primordial se situó en la cima del mundo hacia 1492, debido a su racionalidad científica singularmente genial, a su inquietud racional y a sus cualidades democráticas y progresivas» (2006: 18). Estas son características que casi nadie cuestionaría en Australia (y quizás tampoco en Argentina) como algo esencial y típicamente occidental.

Por ende, deseamos dejar claro que, para nosotros, todo pensamiento está geoculturalmente situado. Si Kusch piensa y siente en torno a lo local es también para llevarnos a reflexionar sobre el mundo, abriéndonos surcos y caminos, invitándonos a pensar y a actuar. Ya había sugerido esto Eduardo A. Azcuy en su prólogo a Kusch y el pensar desde América (1989) cuando dice que Kusch nos convida «a pensar América desde América» $\sin$ que ello constituya «una presunción localista» puesto que «significa una reivindicación del pensar mismo concebido como algo genuino y universalizante». Y recalca: «por histórica ironía ese pensar se convierte así, en esta hora de crisis de la humanidad, en un pensar para el mundo» (1989: 7).

Es justamente esta última observación de Azcuy la que a nosotros nos motiva a pensar en Australia cuando leemos a Kusch cuando estamos viviendo en este país. Pues la fuente del pensamiento kuscheano es inagotable, y esto se debe, a que nuestro autor tiene una cualidad tonal altamente contagiosa para el lector dispuesto a abrirse a sus meditaciones, muchas veces plasmadas en un lenguaje literario, poético y aforístico. ¿Y qué es la sensibilidad poética si no es una razón y un lenguaje cargado de asombro? El asombro brinda la necesaria apertura y distensión en el entendimiento, despojándonos o desarropándonos de nuestros propios pre-juicios. «El asombro pensante habla en el preguntar» (1994: 227), dice Heidegger en «Aletheia». Y este es el principio que guía el pensamiento crítico de Kusch.

Estas capacidades le permiten desarrollar al autor de La seducción de la barbarie una serie de categorías de pensamiento que nos pueden ayudar a pensar y sentir nuestro presente, sea en Australia o bien en Nueva Zelanda, por ejemplo. Ciertas categorías como hedor, pulcritud, historia grande y pequeña, mero estar, (afán de) ser-alguien, el 
patio de los objetos, son conceptos que nos abren posibilidades para adentrarnos a realidades de la condición humana en otras latitudes.

Por cierto, quienes participaron en la colección conmemorativa que prologa Azcuy es muy probable que vislumbraban los dramáticos cambios que estaban por estallar en 1989. El final de la guerra fría y la victoria (incierta) de los EEUU significaba que su pax americana — «nuevo orden mundial»— dependía de su fuerza bélica en el ámbito geopolítico. Pero nuestras lecturas de Kusch nos indicaban que algo más profundo estaba en juego en los altibajos de la historia pequeña. Explica Kusch que la historia pequeña «surge de la complicación adquirida por el hombre del utensilio [...] porque es la de la especie encerrada en el patio de los objetos» (1962: 136-137). Y añade, «tiene algo de esa soberbia del plano del ser alguien, porque pertenece a una élite que finge la ira divina y sustituye a los dioses, fomenta la industria y el comercio y se radica en las capitales» (1962: 137-138). Cuando interpretamos dichos acontecimientos con estos criterios kuscheanos, nos damos cuenta de que lo que estaba en juego era la supremacía de un pensar causal más refinado técnicamente, pues ambos sistemas, el capitalista y el del socialismo real, se preocupaban puramente de la exterioridad material del ser humano, como si este fuese unidimensional.

Kusch se apropia del concepto del «patio de los objetos» de Nicolai Hartmann para hacer del mismo uno de los pilares de su interpretación de la modernidad occidental, centrado en la ciudad. Precisa Kusch: «El espacio vacío tenía una finalidad y era la de crear un campo libre para los objetos, gobernados por la inteligencia. $\mathrm{Y}$ estos no eran solo reales, sino también ideales [...] porque jugaban a la creación de una segunda naturaleza» (1962: 128). Subraya, por lo tanto, «la ciudad se fue convirtiendo en un patio de los objetos» (1962: 129).

En el mundo actual, donde se sobrepone la lógica del capitalismo de mercado, ocurre algo singular que ha llegado a su apoteosis y que Kusch bosqueja en América profunda. En sociedades donde la religiosidad (como interioridad) ha fenecido, ha sido sustituida por una fe o culto a los objetos. Subraya nuestro autor: «El mundo exterior, y su culto nos permite distraernos de nuestra intimidad. La ciencia, que es el culto al objeto [...] sirve al hombre moderno para escabullir su intimidad y hacerse duro y hasta mecánico» (Kusch, 1962: 189-190). En países que se consideran altamente avanzados (como Australia), esto ya se vive como una especie de moral y ética. Los objetos como exterioridad se viven como una razón de ser por la cual vale morir. Un estilo de vida que el mundo anglo-americano defiende a muerte, como así lo manifiesta el credo del ejército de tierra estadounidense: «I am an American soldier. I am a guardian of freedom and the American way of life» (US Army https://www.army.mil/values/soldiers.html). ¿Acaso no es la guerra contra el terrorismo articulada como la defensa de nuestro way of life? 
Para quienes habitamos el apogeo del capitalismo de mercado estamos, de por sí, cooptados a vivir y morir según la consigna que es la piedra angular del sistema: «Consume, serás libre y feliz». Como sujetos del sistema imperante vivimos hoy con plenitud esta nueva religión, cuyos templos son los shoppings y los malls. Con la desaparición de los dioses, sugiere Kusch, «el sucedáneo es la manera de llenar el vacío que queda al otro margen del ciudadano [...]. Y el sucedáneo con fines narcotizantes se da porque la vida urbana actual ha despertado instintos primarios que antiguamente en la Prehistoria se solucionaban con la religión» (1962: 154-155). Y agrega enfatizando: «Así estamos ante un mundo que necesita compensaciones para poder vivir. $Y$ una de las grandes compensaciones consiste precisamente en reemplazar a la religión por la tecnocracia, como otra forma de mitología colectiva [...]. [La] historia de Occidente, es la historia de la sustitución de las cosas de la vida por la de los objetos y el triunfo de la ciudad como forma exclusiva» (Kusch, 1962: 155).

Pues entonces el hombre moderno busca compensaciones en cosas y en técnicas que solucionen todo: tanto su interioridad (Prozac o serotonina) como su exterioridad; mediante políticas tecnológicas pulcras que alivien al ecosistema o, absurdamente, en utopías tecnológicas de ciencias espaciales que materialicen nuestros sueños y nos transporten a colonizar planetas a varios años luz luego de haber estropeado y hecho inhabitable el nuestro.

Dejarse estar o el mero estar no es una opción en nuestras sociedades ultra-modernas, aunque quizás sea la única manera sabia de sobrevivirlas.

A esta altura la lectora o el lector seguramente se preguntará, ¿y qué tiene que ver todo esto con leer a Kusch en Australia? Pues, simplemente, todo. Cuando uno lee a Kusch en Australia, no se puede dejar de hacer una lectura sincrónica, transversal, horizontal: leyendo sobre América, pensando en Australia; leyendo sobre América y pensando en el mundo. Quizás será que nuestra lectura esté condicionada un poco por nuestra doble conciencia de inmigrante; la de habitar entre mundos.

Un ejemplo de este tipo de lectura sincrónica o transversal se desprende de algunas reflexiones en su escrito «Cultura y liberación», donde nuestro autor se explaya sobre el desarrollo de la modernidad argentina que emerge en el siglo XIX, cuyas fundamentaciones podrían amoldarse adecuadamente al contexto australiano:

La verdad de la cuestión es que la cara oficial del país fue elaborada por una minoría heroica. Procede de la ideología de los mercaderes occidentales de acuerdo con la concepción del mundo del siglo pasado (xIx), y cuyo credo entraba la posibilidad de digitar el universo. A partir del iluminismo francés se crea la democracia, se desenmascaran los misterios del universo, se consulta la enciclopedia para ver cómo está hecho el mundo y 
se piensa cuáles son las causas de los males para extirparlos cuanto antes. La vida se convierte en una maquinaria que es fácil de corregir (Kusch, 2012: 21-22).

Al leer esto, entonces, uno comprende por qué hoy Australia es el ejemplo paradigmático de lo que la élite liberal argentina quería y quiere crear en Argentina (y quiere que el país sea). Es decir, aquello que tanto se vocifera y ventila hoy en la prensa porteña, lo de querer ser «un país normal» (como si los hubiese). Pero lo que ocultan las fáciles comparaciones entre Argentina y Australia, es la distancia que mide la historia de una y de otra nación y su papel en el entramado de la geopolítica mundial. Los próceres que idearon y fundaron el país sudamericano con patrones europeos escamotearon el tremendo peso de colonialidad que sojuzgaba a sus propias subjetividades y al país, y que los nuevos poderes imperiales iban a profundizar aún más desde el siglo xix. Aunque Argentina consiguiese su independencia de la corona española, por voluntad propia su élite, caería bajo el poderoso encantamiento del logocentrismo imperial británico hasta mediados del siglo xx. Su desarrollo capitalista, según los patrones de este sistema, no alcanzarán a los de Australia hasta bien entrado el siglo xx porque Argentina seguirá siendo un país dependiente, mientras que Australia cumplirá su papel de copartícipe — hasta la fecha - en la alianza imperial británico-americana en defensa del llamado «Mundo Libre».

Pero también una lectura sincrónica de Kusch sirve para meditar sobre ciertas intuiciones que hemos venido desmenuzando. Una de ellas tiene que ver con sus preocupaciones centrales en torno a la filosofía americana o argentina: «Nuestro problema americano - dice Kusch en 'Cultura y época' - no consiste en que nuestra realidad es indómita, sino antes bien en el hecho de que no tenemos formas de pensamiento para comprenderla» (2008: 140).

En Australia, esta reflexión no parecería tener cabida, por la simple razón de que no se contempla, ya que la filosofía en Australia está enraizada en el racionalismo liberal, sin más. Los departamentos de filosofía en las universidades australianas imparten Filosofía Continental Europea o Lógica (del racionalismo británico). Steve Muecke, en su artículo «Australian indigenous philosophy», afirma: «In departments of philosophy the tradition continues to be European...There is no Australian philosophy, Indigenous or otherwise» (2011: 2). Para la academia australiana los pueblos originarios no tienen filosofía. Quizás esto se deba, en gran parte, a que Australia no necesita su propia filosofía porque ya se ha definido a sí misma, geo-política y culturalmente, como parte integral del circuito imperial anglo-americano. Australia defiende una matriz de poder acorde a su estilo de vida, que pone el énfasis en la supremacía en un anglosajonismo liberal y democrático, que garantice su posicionamiento geopolítico regional y mundial. 
Ahora bien, leer por ejemplo América profunda y emprender una exégesis de este texto fijando nuestra mirada en nuestra vivencia australiana, pero también sintiendo el ámbito emocional que ello implica, despierta en unos interrogantes críticos; interrogantes informados por las categorías kuscheanas como hedor y pulcritud. En este texto fundamental de su obra, Kusch desarrolla estas categorías sumamente útiles para comprender las sensibilidades de la élite burguesa que construye sus propios mitos de pulcritud y hedor:

«El hedor de América es todo lo que se da más allá de nuestra populosa y cómoda ciudad natal. Es el camión lleno de indios...es la segunda clase de algún tren y lo son las villas miserias [...] que circundan a Buenos Aires [...]. [De] tal modo que siempre vemos a América con un rostro sucio que debe ser lavado para afirmar nuestra convicción y nuestra seguridad [...]. Las categorías básicas de nuestros ciudadanos consisten en pensar que lo que no es ciudad, ni prócer, ni pulcritud no es más que un simple hedor susceptible de ser exterminado [...]. La primera solución para los problemas de América apunta siempre a remediar la suciedad e implantar la pulcritud» (1962: 12-13).

Como podemos ver, estas son categorías que emergen de sentimientos emocionales que luego se expresan en actitudes y hasta en políticas sociales. Esto indica que a veces categorías abstractas quizás también respondan no tanto al ámbito cognoscitivo lógico-racional, sino a intuiciones o sentimientos que concuerdan con las expectativas y aspiraciones de ciertos sectores sociales para afianzar su poder, así como justificar sus prejuicios y posición social.

Recordemos que Australia fue fundada como una colonia penal, desde su primer asentamiento en 1788 hasta 1868. Este hecho histórico marcó al país desde entonces. Gran Bretaña se deshizo de lo que su pulcra elite industrial y financiera, así como su nobleza terrateniente, consideraban el hediento hedor visto como una carga a su pulcra sociedad industrial (es la Inglaterra retratada por Charles Dickens). Bajo el velo de la caridad cristiana, desde 1870, esta política británica de despojarse de su hedor, era también parte integral de su política imperial y colonial. De ahí que trasladó a cientos de miles de huérfanos o niños de la calle a sus colonias en Australia, Canadá, Nueva Zelanda y Sud África. En el periodo de entreguerras en el siglo xx quedó en desuso, pero se volvió a restituir desde fines de los cuarenta hasta fines de 1960s.

Con el paso del tiempo, los colonos y sus descendientes querrán hacer de Australia una Gran Bretaña en el Pacifico sur. A medida que despojaban a los pueblos originarios de sus tierras y sus ámbitos de vida, el colono británico inventó su propio mito de pulcritud para marginar o decimar el otro hedor; rechazando todo aquello que hiede de 
aborigen y también de mestizo. Esta es la pulcritud de la modernidad australiana que se traduce en razón de estado con el nombre de White Australia; la política de Australia Blanca que se impone desde 1901 hasta 1973. Esta política ocasionó un profundo proceso de colonización interna en el país, que se materializó en la institucionalización de niños aborígenes, muchos de ellos mestizos, hijos de madres aborígenes. Forzosamente quitados de sus madres para «blanquearlos» culturalmente; sea en familias anglo-australianas o bien en instituciones religiosas (donde sufrieron vejaciones sin nombre) ${ }^{1}$.

Aquí merece la pena detenernos un momento, porque el concepto de pulcritud de Kusch nos ayuda a esclarecer una noción coyuntural en la cultura colonial australiana: el del mito de la blancura de raza. Dicho mito y su resabio hoy es un residuo del sentimiento de superioridad civilizadora anglosajona que fundamenta su discurso imperial, así como el de atribuirse una humanidad excelsa, a la que deberían alcanzar los otros. Esta es la piedra angular de esta pequeña historia del mundo que pretende liderar el circuito imperial anglo-americano, adjudicándose la misión manifiesta de defender la libertad y la democracia parlamentaria como valores supremos de una civilización pulcra. Una civilización que hoy es sinónimo del capitalismo de mercado.

Este sobredesarrollado sentido de pulcritud traducido a blancura racial como lógica subyacente del humanismo civilizatorio anglo-americano es el que nos ayuda a aproximarnos a una de las llagas de la Australia contemporánea (y de su colonialidad interna). Esta herida es el maltrato de refugiados que llegan a las costas australianas desde Oriente Medio. Escapando con sus vidas del infierno causado por las políticas anglo-americanas de las que Australia es partícipe; arriesgando sus vidas cruzando territorios y mares para llegar indocumentados a este país. Hombres, mujeres y niños que llegan en barcas para luego naufragar en «centros de detención» en islas aisladas del Pacifico. Estos fenómenos y sus secuelas se podrían interpretar como el de una herida colonial; las secuelas de la colonialidad que generan interna y externamente las políticas de este país.

Para alguien que vive entre culturas e idiomas, y habita entre realidades, leer a Kusch otorga otro modo de interpretar su pensamiento, y el mundo que habitamos. Y esto es algo que Kusch, habiendo sido hijo de inmigrantes y estando entre idiomas y lugares —el urbano y el puneño- también tiene que haber vivido. Leer a Kusch en y desde Australia con una consciencia de inmigrante, de estar un poco acá y otro poco allá, un poco dentro y fuera de lugar, es la de ser consciente de que uno no comparte — como diría Walter Mignolo (2011: 108-109)— las regulaciones de la modernidad del país adoptado y tampoco del otro; de ser un buen burgués consumidor y de aceptar ale-

\footnotetext{
${ }^{1}$ Véase Bringing Them Home Report (1997), informe del Australian Human Rights Commission.
} 
gremente aquello de la cultura del mainstream: «consume, serás libre y feliz». Tener una conciencia de inmigrante es vivir en tensión. Como dice Gloria Anzaldúa: «El choque de un alma atrapada entre el mundo del espíritu y el mundo de la técnica a veces la deja entullada [harta]» (2007: 100).

Por tanto, el camino que elije Kusch, de dejar Buenos Aires y adentrarse en ese mundo andino, tan lejos de aquél (espacial y temporalmente), es también entrar en una condición existencial tensa, por ser crítica, pues conlleva la marginalidad en la metrópolis; doble marginalidad por ser hijo de inmigrantes. Pero esta marginalidad le confiere a nuestro autor la ventaja del descubrimiento crítico de los estamentos de una cultura burguesa de clase media urbana que él mismo lleva en su formación. La consciencia de esto es un autocuestionamiento que le permite articular una crítica a la modernidad.

Hay otro elemento que es importante y a la vez subyacente en nuestra lectura de Kusch en y desde Australia. Pues nos aventuramos a afirmar que una lectura hecha en estas latitudes es una lectura hecha desde el sur, lo cual indica una muda en el punto de referencia, y, por eso, hablamos de la lectura sincrónica. Kusch nos permite hacer este malabarismo exegético porque cada vez que nos sumergimos en su pensamiento y en su obra nos encontramos no solo con el antropólogo y el filósofo, sino que nos da la mano el entendimiento del poeta. Pues, en esos momentos, en nuestra lectura, hallamos su mirada asombrada e inquieta. Y el verdadero poeta, como hemos dicho, está siempre libre de anteojeras, pues su guía es la intuición (la intuición del asombro / el asombro de la intuición) y la apertura hacia la alteridad y ¿por qué no?, al misterio; a lo desconocido.

Con estas reflexiones hemos querido invitar al lector a emprender su propia lectura de la obra kuscheana, cuyo pensar singular y novedoso nos da otra apertura de entendimiento del mundo que habitamos.

\section{BIBLIOGRAFÍA}

Anzaldúa, Gloria (2007). Borderlands / La Frontera. The New Mestiza (3 ${ }^{\mathrm{a}}$ ed.). San Franscisco, CA: Aunt Lute Books.

Azcuy, Eduardo A. et al. (1989). «Prólogo». En Kusch y el pensar desde América, Buenos Aires, Fernando García Cambeiro.

Australian Human Rights Commission (1997). Bringing them Home. Report of the National Enquiry into the Separation of Aboriginal and Torres Strait Islander Children from Their Families, disponible en: https://www.humanrights.gov.au/publications/ bringing-them-home-report-1997 (consulta realizada en diciembre 2017). 
Dussel, Enrique (2016). Filosofías del Sur. Descolonización y transmodernidad. Buenos Aires: Akal.

Heidegger, M. (1994). Aletheia. En M. Heidegger, Conferencias y artículos. Barcelona: Ediciones del Serbal.

Hobson, J. M. (2006). Los orígenes orientales de la civilización de Occidente. Barcelona: Critica.

Kusch, R. (1975). América profunda (2 ${ }^{\mathrm{a}}$ ed.). Buenos Aires: Editorial Bonum.

- (2012). «Cultura y Liberación». En Esbozo de una antropología filosófica americana. Rosario: Editorial Fundación Ross.

- (2008). «Cultura y época». En La negación en el pensamiento popular. Buenos Aires: Editorial Las cuarenta.

Mignolo, Walter (2011). The darker side of modernity. Global futures, decolonial options. Durham: Duke University Press.

Muecke, Stephen (2011). «Australian Indigenous Philosophy», Comparative Literature and Culture 13.2: http://docs.lib.purdue.edu/clcweb/vol13/iss2/3/ (consulta realizada en diciembre de 2017).

Royal Commission into Institutional Responses to Child Sexual Abuse (2017), disponible en: https://www.childabuseroyalcommission.gov.au/final-report (consulta realizada en diciembre de 2017).

U.S. Army (s/f). «Solder's Creed», disponible en https:/www.army.mil/values/soldiers. html (consulta realizada en diciembre de 2017).

Vargas Llosa, Mario (2005). «América latina: la utopía mestiza», La Nación (Buenos Aires), 18 de diciembre de 2006, disponible en: http://www.lanacion.com. ar/765736-america-latina-la-utopia-mestiza (consulta realizada en diciembre de 2017). 